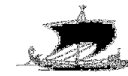

$\mathrm{H} \quad \mathrm{K}$

I T H A K A R E P O R T

COMMISSIONED BY JSTOR

\title{
Scholarly Communications in the History Discipline
}

A Report Commissioned by JSTOR

Created August 31, 2006

Ithaka Strategic Services

Authors:

Rebecca Griffiths, Michael Dawson and Matthew Rascoff 


\section{NOT E}

This is an edited version of a study commissioned by JSTOR in 2006. It is being shared as the research presented here may be of interest to others in our community or beyond. For more information about this report or others in this series, please contact Heidi McGregor, Director, Marketing \& Communications (heidi.mcgregor@jstor.org). 


\section{I . E X E C U T I V E S U M M A R Y}

This paper presents the findings of a study of scholarly communications in the discipline of history, focusing on the resources and processes historians use in their research. It complements a previous investigation of the field of economics, and thus illustrates the differences between these disciplines. The methodology was essentially the same: we relied primarily on interviews with senior and junior faculty and graduate students from a mix of different institutions. We found that the responses seemed to converge fairly quickly on a few themes.

One theme was that books are still the preeminent form of scholarly communications in history, and that publishing one to two books is critical for attaining tenure in institutions with a research focus. However, there may be some cracks in this edifice in the sense that journal articles and a derivative of monographs - book reviews - are the main secondary sources used for research. While journal articles are significantly less valuable for career advancement, they have become more easily accessible than monographs and thus a more convenient resource for research. There are also concerns about the viability of the reliance on monographs in view of the flagging health of monograph publishing programs in university presses.

A second theme was that the transition from print to electronic is happening slowly in history relative to other fields. Many leading journals, especially outside the U.S., do not provide current issues and / or back issues online. There are few online-only or open access journals, and little sharing of preprint papers. Very few monographs are available electronically, and e-books are not assigned the same scholarly status as print books. Only a miniscule portion of primary source materials have been digitized, though we are starting to see some efforts at making finding aids of archives more accessible online. Finally, effective and scalable models for creating new forms of historical scholarship that take advantage of the online medium have yet to emerge. The relatively slow pace of change presents difficulties for training the next generation of historians, as undergraduates of today arrive with a mindset that anything not available electronically does not exist.

A third theme was the importance in history of comprehensiveness. While one prominent economist actually discourages his students from reviewing past work done on a particular topic for fear it might discourage them or impede their creativity, historians emphasize the need to fully understand the context of an argument, where it sits in an ongoing scholarly dialogue, and the primary materials upon which it draws. Historians' discovery process therefore tends to be wider-ranging and to cover lesser-known sources; they aspire to discover untapped sets of data or primary materials upon which to base their analyses. 


\section{I I I N T R O D U C T I O N A N D M E T H O D O L O G Y}

The objectives of this study were (1) to develop a general understanding of the tools and processes historians use in their research; and (2) to understand the role that journals and other types of resources play in the field of history. The report provides an overview of the resources used in history and how these have evolved and describes how historians go about their research and where they encounter sources of friction.

In total we interviewed 26 people from a variety of institutions and fields ${ }^{1}$ : eight from Ivy League institutions, ${ }^{2}$ nine from non-Ivy League institutions, ${ }^{3}$ one from Cambridge, four librarians, and three staff members from a history museum. We concentrated the majority of our interviews on scholars of American and European history, but also included several area studies historians to get a sense of the differences in research approaches. Interviewees were focused on the following areas: two on ancient Western history, two on medieval history, six on American history, two on the American South, one on African-American history, three in British history, three on France, three on other areas of Europe, one on Africa, one on China, and one on Latin America. In addition to their primary specialties, two also work on world history, two work on diplomatic history, two look at the history of technology, and two work on gender. Our pool of interviewees included eleven senior faculty (of which two were actively involved in new forms of electronic publication); current presidents of the American Historical Association (AHA) and the Royal Historical Society; a past head of the Organization of American Historians (OAH); the founder of Valley of the Shadow Civil War website; and the Director of the Center for History and New Media at George Mason University. It included four junior faculty, four graduate students (one with expertise in scholarly communication; and one who serves as assistant editor of the Journal of American History), two museum curators, one archivist, and four librarians specializing in history.

In addition, we drew from a number of secondary sources, particularly reports on the field of history published by the AHA. These explored the challenges associated with journal and monograph publishing, the forms of electronic publication in history, and the need to reform graduate education of historians.

The findings described here are not based on a quantitatively robust sample size. Much of what we heard was fairly consistent across all or most people interviewed, and on these points we feel comfortable making some generalizations. We will share interesting comments heard from a smaller number of interviewees, noting that this does not necessarily represent the views of a broader group, and we will also highlight areas where we heard a range of opinions.

1 See Appendix A

2 Brown, Columbia (3), Harvard (2), University of Pennsylvania, Yale

3 Arkansas Tech, George Mason (2), Indiana - Bloomington, University of Iowa, University of Memphis, University of Nevada Las Vegas, University of Virginia, Washington University of St. Louis 


\section{I I . O V E R V I E W P R E S E N T A N D F U T U R E}

The main resources used by historians include: monographs, journals (both articles and book reviews), conference proceedings and multi-author volumes, primary sources, abstracting services, and listservs. In this section we will describe each of these in detail. We will also explore factors influencing the pace at which these resources are migrating from print to electronic form.

\section{Monographs}

Simply put, the monograph is still viewed as the most important form of scholarly output in history, and therefore the most important vehicle for getting a job and achieving tenure. One historian argues that books create the foundations of scholarship, while journal papers can be used to elaborate, criticize and defend ideas (what he likened to "leaves on the trees"). There is a sense that the unique form of argument developed in a full length monograph does not exist in journal articles and may be missed if one only looks at one chapter or at a book review, both common practices. Most institutions expect scholars to produce one book for tenure and two for a senior professorship, though the very top institutions like to see two books for tenure and more vocational schools can be satisfied with only journal publications. Another leading historian sees the kind of detailed argument in the monograph as something foundational to history, but for which undergraduates and even some graduate students no longer have patience.

There is no indication that the primacy of monographs is likely to change soon, though there are both old and new arguments in favor of shifting some emphasis toward other forms of publication. One longstanding debate is simply whether too much emphasis is placed on research as opposed to teaching. A second argument is that monographs have become less useful relative to journals because the vast majority are not available electronically. They do not even have good exposure in abstracting services because most book chapters are not indexed. Younger generations of scholars rely so heavily upon electronic resources that content available only in print has little visibility.

A third argument stems from a concern about the perceived "crisis" in history monograph publishing, which is attributed to two factors, as discussed in an article by Robert B. Townsend, Assistant Director, Research and Publications, at the AHA. ${ }^{4}$ First, library budgets have been stagnant or declining, and are squeezed by the price inflation of journals (STM journal prices rose more than 600 percent between 1982 and 2002, while prices for academic books rose only about 70 percent during that period). As research libraries account for 60 to 80 percent of new scholarly monograph purchases, their budget situations are critical for monograph sales. The second set of problems pertains to the health of university presses, which have seen their operating subsidies slashed or eliminated in recent years. University presses produce almost 50 percent of history titles, around 10 percentage points more than in other humanities and social science fields. As average title sales have declined to roughly 300 copies per book, well below the volume required to break even, observers fear that presses will need to reduce the number of books published, making it difficult for the current wave of junior faculty to meet tenure requirements. ${ }^{5}$

Townsend points out that there are some complexities to this picture. First, history as a discipline is actually in better shape than other humanities, such as philosophy and musicology. In 2002 a record number of history monographs were published - roughly 7,500, compared with around 5,500 in 1989. History books are also on the lists of more university presses (87 percent, according to the 2000-01

4 Robert B. Townsend, "History and the Future of Scholarly Publishing." Perspectives, October 2003, pages 32-41. Available online at: http://www.historians.org/Perspectives/Issues/2003/0310/rbtwebarticle1003.pdf. All data cited in this paragraph are from this article. 5 Ibid. 
Association of American University Presses Membership Directory). However, within history some fields, primarily U.S. history, are fairing far better than others. While an increasing percentage of historians are pursuing degrees in area studies (see below), press monographs are headed in the opposite direction. The percentage of presses publishing books in Asian history fell by half between 1981 and 2001 (from 43 percent to 21 percent). Data from Blackwell indicate that nearly half of all titles published are in U.S. history, compared to about 20 percent for European and Asian history and only 4 percent for African history. ${ }^{6}$

According to a prominent historian, the kinds of books being produced are changing. Narrow monographs are out of fashion, and graduate students are taking on bigger and more visible subjects. The people who write narrow monographs have a hard time getting published and getting jobs. At the same time, presses are increasingly reluctant to publish very lengthy books, so authors are being asked to edit down substantial portions of their works. This scholar believes this is more true of less populated fields than of American history (and his view is confirmed by the data cited above). James McPherson, former president of the AHA, wrote that "We know with greater certainty, however, that university presses are more likely to publish titles in American history than in other fields. Thus the young scholar in $16^{\text {th }}$ century French history or pre-colonial Chilean history trying to get her first book published may be out of luck no matter how good the manuscript is."7

\section{Journals}

There has been a proliferation of history journals over the past few decades, reaching 203 in 2000 classified as "Academic/Scholarly." "While the number of history PhDs conferred from 1975 to 2000 climbed by a factor of 1.5 compared to the period from 1960-1975, the number of journals since 1975 has more than doubled. ${ }^{9}$ In contrast, the number of journals in other humanities fields followed a similar growth curve to that of $\mathrm{PhDs}$ conferred. ${ }^{10}$ The growth in the number of history journals is due in part to increasing specialization of journals to address every conceivable field and subfield ("there is a need for a journal on American Communism..."). ${ }^{11}$ Some also argue that there has been an increase in the supply of good content.

The top journals in history, particularly the American Historical Review (AHR), are often criticized as being too "bland" and general to be of much value for researchers, though most historians still browse through them to see what new trends may be emerging in the field, and say they are quite happy to publish in them when the opportunity arises. Other general journals include the Journal of American History, Past and Present, and Annales; beyond those, leading journals vary by area of focus.

Most history journals include both book reviews and articles. Several top journals try to review every book published in history. In 2005, for example, the $A H R$ contained 26 articles and roughly 900 book reviews. Reviews of American History contains only longer (5-7 page) book reviews, which readers seem to find more useful. According to one interviewee, by far the heaviest usage of the $A H R$ and $J A H$ is of book reviews, and that this has been well established since the early 1990s.

Book reviews serve two purposes. One is for scholars to evaluate one another's research in a public forum. Writing book reviews is seen as prestigious, if considerably more time consuming than peer

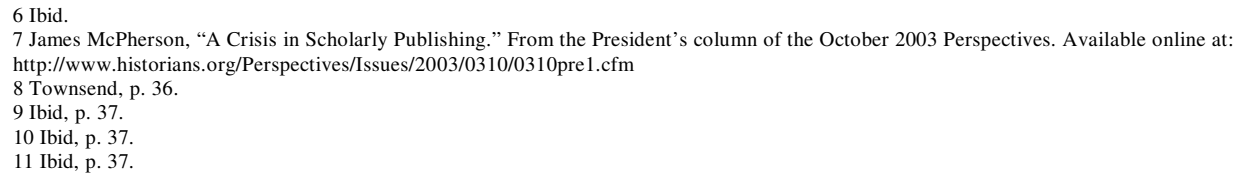


reviewing journal papers. Another is to provide a synopsis of the central arguments of a monograph, allowing scholars to stay abreast of developments in their field (and in history more broadly) and relieving them of the need to read the actual book. Book reviews are seen as having a shorter shelf life than articles, since they tend to relate the book to the current contextual environment.

Journal articles occupy an interesting place in historical scholarly communications. Many interviewees discounted their importance for career advancement (one can get tenure having published monographs and no journal articles, but not the other way around), but most conceded that they are more widely used for research (especially initial research) than monographs are. They are shorter, have abstracts in many cases, and most importantly, are available and searchable online. There is some overlap in the way book reviews are used, as journal papers are sometimes turned into monographs, and therefore can provide a synopsis of the central arguments of the book.

Scholars publish journal papers for a number of reasons. One is to claim a topic or stake out a position in an ongoing debate. Another is to explore a subject of interest that does not seem to merit a full monograph or to test an argument that may later be turned into one. A third is to create a publication record to get an initial job out of graduate school and to begin to build a reputation (though this is a debated strategy), or to show evidence of publication in order to get salary increases. Finally, scholars may publish in journals to get greater exposure for their research, given their wider usage, and to raise interest in a subsequent monograph.

There was little consensus on when in their careers scholars should or do most frequently publish in journals. Some thought that scholars tend to produce journal papers early in their careers, to get published before their first book comes out, and later in their careers, when they are tenured and no longer feel motivated or have too many time commitments to produce full monographs. Others noted that many scholars take a long hiatus after producing their first book before producing a second (and sometimes the second book never materializes), suggesting that they produce more journal articles in mid-career. A couple of interviewees thought of publishing in journals as a good way to establish a record of publication and get a job before one's first book comes out, while others argued that the time it takes to publish a journal article is better used towards producing a monograph, especially considering the time lag for journal publication.

\section{Peer Review}

The peer review process is considered extremely important in history. Referee comments are often solicited by tenure committees, because the breadth of history makes it necessary to rely on the judgment of specialists. We did not hear complaints about the excessive workload created for the "peers" in this system (as we had in economics), and we heard many describe peer review as an important part of the process of refining scholarship. Given that there is very little sharing of non-peer reviewed papers (scholars associate this with the lack of collaborative culture in history), peer review helps the historian improve his or her work before publication. Preprints are rarely circulated, except at conferences. Nonpeer reviewed papers are viewed with some skepticism - people prefer to share, and to read, carefully edited works.

Peer review comments tend to be 2-4 pages and are sometimes included in consideration for tenure. From the time a paper is submitted until publication can be 1-3 years, and this time lag can be an issue for those seeking jobs or tenure. Although the publication process is viewed as rather slow and laborious, possibly blunting the cutting edge quality of work, the delays did not seem to provoke the same concerns or motivation to share preprint works as in economics. 


\section{Conference Proceedings and Multi-Author Volumes}

We heard from several interviewees that one relatively significant change over the past 10-20 years has been the emergence of multi-author volumes. These are compendia of various types of papers (sometimes conference proceedings) around a particular subject. Quality varies widely; some are peer reviewed and well regarded while others have little quality control. One difference from journals is that authors are sometimes invited to submit papers (as with conferences) and their submissions are then included regardless of quality.

Views varied on why publication of multi-author volumes has grown. One scholar argued that, because of increased specialization, individual authors are no longer able to cover broader topics. This sounds valid, but it contradicts the notion that scholars need to write books on broader topics to get published. Another interviewee thought that multi-author volumes were being promoted by publishers because libraries would be more likely to purchase them, while a third argued that publishers actually lose money on these publications. The latter seems less likely to be true, given that the two publishers identified for these types of volumes, Brill and Palgrave, are both commercial. In any case, it does seem likely that some good work is being published in this format, but that these volumes are not easily accessible to most scholars. They are not available online unless published as a journal issue, and we were told that they are rarely indexed, let alone catalogued by author.

\section{Abstracting Services}

Many historians said they rely heavily on abstracting services for discovery, as they are the most comprehensive resources available. America: History and Life (AHL) and Historical Abstracts, both published by ABC-CLIO, were the most commonly cited. Another service, the History of Science, indexes essays in books more consistently, but is viewed as weaker in European content. AHL is a complete bibliographic reference to the history of the United States and Canada from prehistory to the present. Published since 1964, the database comprises over 530,000 bibliographic entries for periodicals dating back to 1954. Additional bibliographical entries are frequently added to the database, such as retrospective coverage of journals issues published prior to 1954. A graduate student noted that $A H L$ sometimes has working links directly to full text articles available through their library.

Published since 1954, Historical Abstracts indexes periodical literature in history and the related social sciences and humanities from around the world. Historical Abstracts currently covers over 1,700 journals published worldwide in over forty languages, with over 720,000 entries from periodicals and with fulltext links to over 135,000 articles and dissertations. Each year, the editors of Historical Abstracts add over 16,000 abstracts and citations, over 3,000 book citations, and over 1,200 citations of dissertations from the current literature and publications. As with AHL, additional bibliographical entries are also added to the database from time to time. Historical Abstracts on the web includes incomplete, in-process entries awaiting abstracts and, in some cases, title translations. One interviewee said that Historical Abstracts is not up to date with current publications, and that it is weak in non-English materials.

\section{Primary Materials}

Primary materials are, of course, the lifeblood of historical research. Most large collections (at least in the U.S. and Europe) have been partially microfilmed, but these tend to be poorly catalogued and inconvenient to use. At present, only a small fraction of primary source materials are indexed online, let alone digitized. A couple of scholars argued that the audience of researchers for any individual document is far too small to justify mass digitization of archival materials. ${ }^{12}$ (One exception is in papyrology, where 
the canon of primary source materials is actually much smaller than the body of secondary materials, and most are available online. This is also true for other areas within classics.) One interviewee expressed a concern that resources are directed toward making documents available in new forms rather than toward "real scholarship." Another concern with online primary resources is the perception that editors select what they find interesting and rip them out of context, making it difficult for researchers to accumulate background knowledge as they do with archival work. Finally, some of the primary collections that have been put online have quality issues, probably due to the condition of the physical materials.

Still, several people said that they have found useful online primary materials. A number of collections of relatively broad interest, such as Valley of the Shadow, ${ }^{13}$ Early English Books Online (EEBO) ${ }^{14}$ the Adams correspondence, and a set of volumes containing ancient Chinese texts, have been digitized. Several scholars cited specific online collections that they find useful in their areas, such as the Harold Macmillan papers and a collection of $19^{\text {th }}$ century newspapers.

These online resources are typically used less for research than for teaching, where there is more emphasis on a core set of documents in a given field, and less need for depth in obscure areas. One professor said that he recently advised a student who produced an entire thesis from electronic materials. At the same time, he noted that scholars themselves rarely cite electronic resources, as doing so would not be perceived as real research.

Despite these reservations, a few historians did show some enthusiasm about the notion of putting archival materials online. It is now common practice for researchers to use digital cameras to photograph archival documents rather than making detailed notes onsite when such photographing is allowed. One interviewee was excited about the idea of encouraging researchers to put these files online, while others thought the rights issues would be too much of an obstacle (often researchers are required to sign statements restricting use of any digital files). Another historian opined that some archives may allow their content to deteriorate, and that digitization provides a means of ensuring that documents are preserved for posterity.

Whether or not primary materials are available online, most serious historians will still want to visit the physical archive. They view themselves in part as professional detectives, and an important part of their skill set is sifting through archives to find unknown gems, understanding the context of a document, examining marginalia, and drawing observations from details that would not be accessible from a digital image. Some also get great satisfaction from handling the physical object. At the physical archives they may also find opportunities to socialize with other historians with common interests. There is also likely a sense that their competitive advantage as historians derives in part from having deep familiarity with a collection that is inaccessible or undiscovered. Those in area studies view fieldwork (e.g. spending months in a remote and obscure African archive) as an essential rite of passage.

A number of historians complained that the primary source materials that are online are not well organized and often difficult to find, especially if one is doing interdisciplinary research. Online finding aids can be very useful, but often difficult to find and of spotty quality. There was a concern about the lack of standardization in the way that both finding aids and documents are being put online. There is no comprehensive aggregation of online primary source materials for all of history and no well organized collections in many subfields (one might argue that these are unrealistic goals). The most broad-based attempt to organize finding aids online appears to be ArchiveGrid, produced by RLG, which was

13 See The Valley of the Shadow: Two Communities in the American Civil War, available online at http://valley.vcdh.virginia.edu 14 See http://eebo.chadwyck.com. 
mentioned by several interviewees, though they did not use it regularly. ArchiveGrid claims to include finding aids from around 3,000 archives in North America (out of a total of 5,000) as well as some foreign archives, though it is not clear what portion of those archives' holdings are covered. ${ }^{15}$

\section{Listservs}

Every historian with whom we spoke uses some component of H-Net. It can serve as a forum for dialogues about a current topic of interest, but we heard that some lists can also be politicized by extremists. Many historians use it to post more basic questions (e.g. "does anyone have a book recommendation for this class I'm teaching"). It is rarely used to share preprints or as a tool for more substantive scholarly communications.

\section{Transition from Print to Electronic}

Robert Townsend has noted that there are three levels of electronic formats. One is just putting text online. A second entails linking that text up with other primary and secondary sources on the web for illustrative purposes - basically a traditional article with some attached archive. There are some examples of this in the Gutenberg-E and ACLS History E-Book projects (described in more detail below). A third level is described by Townsend as "reconceptualized," such that "texts are built 'from the ground up' and fully integrate other electronic resources into their arguments." 16 There does not, at present, seem to be much appetite among scholars to learn a new way of consuming history, as would be required by the third level. Among other difficulties, papers tend to be read in print even when accessed electronically, and the benefits of seamless integration among electronic resources are somewhat muted when the reader must jump back and forth between the print and electronic versions.

History seems well behind the sciences and social sciences in making the transition from print to electronic format. As Townsend said, people do not go into history to be on the cutting edge of technology, and therefore change is likely to be incremental rather than revolutionary. Monographs are still almost entirely in print, as are nearly all primary sources. Many journals, including leading ones in some fields, still have not made current issues available online, primarily for fear of losing society members and print subscriptions.

The U.S. is actually far ahead of other countries in terms of digitizing both current issues and backfiles. European journals are almost all still available only in print. There are two sites for French Journals: Revues (http://www.revues.org/) and CAIRN (http://www.cairn.info/accueil.php), though Annales, arguably the most important historical journal in European history, is not available on either site. (We heard that Annales was considered the most important history journal from the 1920s through the 1970s, during a period when historians were expected to be proficient in French.) In France, the Bibliotheque Nationale has abundant resources, and at one point actually launched a project to digitize its entire collection, but apparently abandoned it because the scope was too broad (and perhaps also because the intellectual property regime in France is quite restrictive). Recently it has started to put some materials online.

History has also been slow to produce electronic scholarship. A general impediment to the creation of online resources is the lack of recognition of scholarly value in this kind of undertaking. A number of interviewees noted that advancement decisions are still based on print monographs, and that electronic books would not carry the same weight.

15 See http://www.archivegrid.org.

16 Robert B. Townsend, “All of Tomorrow's Yesterdays: History Scholarship on the Web”. Perspectives, May 2002. American Historical Association. Available online at: http://www.historians.org/perspectives/issues/2002/0205/0205pub3.cfm?pv=y 
Very few books are available electronically, and many scholars are still skeptical about the quality of ebooks, which are thought to be books that were not good enough to be published in print. The Gutenberge project was launched through a collaboration of the AHA and Columbia University Press, both of which saw it as an opportunity to develop a new model that could "save" the history monograph. ${ }^{17}$ Its goal was to publish revisions of prize-winning dissertations as electronic books along with embellishments that could not be conveyed in print: extensive documentation, hyperlinks to supplementary literature, images, music, video, and links to related web sites. Those consulted for this study generally considered the project to have had somewhat disappointing outcomes, as the costs and time required to produce books in this type of format were felt to be out of proportion to the value created, and out of reach for most historians. Thus it failed to create a model that could be widely replicated. One interviewee thought it would have been more successful if print-on-demand had been offered as an option from the beginning, rather than introduced only late in the project. But the print medium would seem to sacrifice much of the functionality and supplementary content.

The other major e-book project undertaken in history was the ACLS History E-Book Project, a collaboration of eight learned societies, nearly 75 contributing publishers, and librarians at the University of Michigan's Scholarly Publishing Office, to create an online, fully searchable collection of high-quality books in history. The books have been recommended and reviewed by historians and are supplemented by free, downloadable MARC records. We did not hear much feedback on this effort.

In addition to these two content focused projects, a couple of initiatives are focusing on providing the tools needed to hasten the transition from print to online. One, Archivists' Toolkit, is a project run by NYU and UCSD to develop a set of open source software tools that archivists can use to process records and make them more accessible to researchers. Another is an effort by Roy Rosenzweig's Center for History and New Media to build a tool called Firefox Scholar. ${ }^{18}$ This is a client application that, among other things, would allow scholars to upload the documentary basis of their work. The content would not have to reside on one server, but it would have to be "networkable" and "sharable" to be of maximal use to the community.

The relatively slow pace of transition to electronic journals is due in large part to concerns among publishers of lost revenues. We heard that print subscriptions have fallen significantly for journals that are available online; for example, one university reduced its subscriptions to a major history journal from seventeen copies to three, and these are mainly viewed as a backup to the electronic version. Some schools and individuals have cancelled print subscriptions completely, and individual society memberships are declining. That said, users seem to have more use for print journals than economists did - many still have print subscriptions through their society memberships, and they were more likely to tell us that they like to skim their print copy of the $A H R$ or $J A H$.

Several publishers of history journals that wanted to put their current issues online decided that the existing alternatives did not meet their needs. The AHA, the University of Illinois Press, the Organization of American History, and National Academies Press decided to create the History Cooperative as a platform for electronic current issues.

17 Patrick Manning, "Gutenberg-e: Electronic Entry to the Historical Professoriate." From The American Historical Review, Vol. 109, No. 5, December 2004. Available online at: http://www.gutenberg-e.org/aboutframe.html.

18 [Editor's Note: Since the original publication of this report in 2006, the Firefox Scholar project changed its name to Zotero.] 
A few e-only journals exist. One is focused on early America, but casts itself as a different type of forum (see http://www.common-place.org/). Another is a well-known example in classics, the Bryn Mawr Classical Review (http://ccat.sas.upenn.edu/bmcr/), which grew out of a free print publication and is open access.

Interviewees voiced some dissatisfaction with the current state of affairs. They are particularly keen to see more secondary materials, especially journals, available online. They would also like to see more monographs online, but seem to feel less urgency (perhaps because they equate e-books with lower quality). They worry that for undergraduates "if it isn't electronic, it doesn't exist." There is thus a growing disconnect between the conservatism in history and the expectations of the next generation of students. While historians may accept the necessity of relying heavily on print primary materials for the foreseeable future, secondary publications that do not make the transition will find themselves becoming increasingly irrelevant in the longer term. 


\section{V. H O W H I S T O R I A N S D O R E S E A R C H}

Historians are extremely concerned with the ongoing "conversation" or "dialogue" related to their area of interest. From the thesis of their arguments all the way to a scrap of paper in an archive, they are trained to study what happened before and after to properly understand how the noise around the argument or the piece of evidence affects their interpretation. They are required to examine both primary and secondary sources in nearly every instance of research. The emphasis on context also requires comprehensive research, which ideally is bounded only by the scope of the topic, though of course time constraints and access to resources play a role in limiting research. This approach is notably distinct from that of "public" or "popular" historians, who tend to write in more of a contextual vacuum and to address a broader audience.

These "conversations" can take place over long periods of time (one scholar said research from the past 15-20 years is viewed as "current" thinking). More recent journals tend to be about approaches. Older publications are useful to understand the longer term context and for the data they may provide (possibly in footnotes). They may also be viewed more as primary than as secondary sources. Undergraduates are typically expected to read only the more recent publications, but graduate students and faculty are expected to understand the full dialogue over time in their specialties.

Over the past few decades, more scholars have pursued area studies and fewer specialize in U.S. and European history (despite the opposing trend in monograph publication). ${ }^{19}$ Historians are also doing more international work and making more of an effort to put the events of their country of focus in an international context. Research methodologies are fairly similar between areas of study. One notable difference among area studies is that scholars of regions such as Africa, where many countries do not have strong written traditions, tend to blend more interdisciplinary techniques such as ethnography and sociology. They base more of their research on interpretations of material and popular culture, oral histories, and other non-written resources. Still, most area studies faculty (including history of science) have history appointments. Museum historians, some of whom are expected to publish, also tend to have a greater focus on artifacts and material culture. At the other end of the spectrum, scholars of areas such as classics work from a defined set of primary texts, rather than sifting through archives of forgotten documents.

New topics for research sometimes arise in response to the "dialogue." Scholars may also maintain a list of ideas in which they are interested, and then only place these in context once the research project has begun. History tends to be a very individualistic field, and several scholars conceded that it is not collaborative in the same way as economics or sciences, though they have noticed modest moves in that direction (which they seem to perceive as a positive thing).

Research is divided between primary or secondary searches. These resources can overlap, as with very old journals, but for the most part different sources are used. Secondary literature can be divided into monograph, multi-author volume searches (though we did not hear that the latter are often used for research), and journal searches. Searches for monographs and multi-author volumes are often conducted through the library catalogue and WorldCat. Journal searches tend to begin at JSTOR or an abstracting service (those in American history use the abstracting service America: History and Life and those in European history tend to use the Historical Abstracts). The latter generally include book and dissertation citations in addition to journal citations. Those who use JSTOR for discovery tend to be satisfied with the

19 Robert B. Townsend, "History and the Future of Scholarly Publishing." Perspectives, October 2003, pages 32-41. Available online at: http://www.historians.org/Perspectives/Issues/2003/0310/rbtwebarticle1003.pdf. 
search and full text content. They typically use Project Muse and the History Cooperative for current issues. Those who start their searches in abstracting services do so because they prefer a comprehensive search of current and back issues, and because they feel that the JSTOR archive does not contain all the journals they need, especially non-U.S. ones.

Scholars typically learn about primary source collections through footnotes in existing papers or books, advisors, colleagues, finding aids, and simply visiting and digging through archives. Scholars are beginning to use online searches for certain types of primary content, but in general historians rely far less upon Google than economists. It is used mainly for hunting down quotations or for targeted information searches, such as to verify "facts" and find citations and CVs. It is also sometimes used to hunt down specific quotes from e-books, particular of known online resources such as Early English Books Online and Eighteenth Century Collections Online. Google is rarely used as a starting point for discovery due to the surfeit of junk that comes back. As one can imagine, a search for "eighteenth century slave trade" is likely to turn up more uneven results than for "estimated propensity score." Interestingly, few historians had even tried Google Scholar, and most of those that had found it disappointing.

We did not uncover a great deal of interest in making journals open access or feeling that "information wants to be free." This lack of momentum was somewhat surprising given the AHA's decision in October 2005 to make all articles (but not book reviews) in the AHR openly available. We were told that this decision was motivated by a desire to widen the audience for serious history writing and draw in nonhistorians. It is not yet clear what the impact of going open access has been on the AHR's usage. The AHA recently made a push to get the articles indexed by Google to increase the journal's visibility.

We did come across a couple of areas with more interest in open access, namely Africanists and public historians, who are sometimes outside the academy yet are doing "real history" recognized by the academy. The African Studies Association has a panel on open access at its annual conference, and we heard that this session tends to be well attended by frustrated African scholars who lack access to all types of resources in their home institutions. Non-African scholars recognize the difficulties their African colleagues face and are supportive of making content freely available in Africa, though they do not seem to feel that resources need to be free everywhere. 